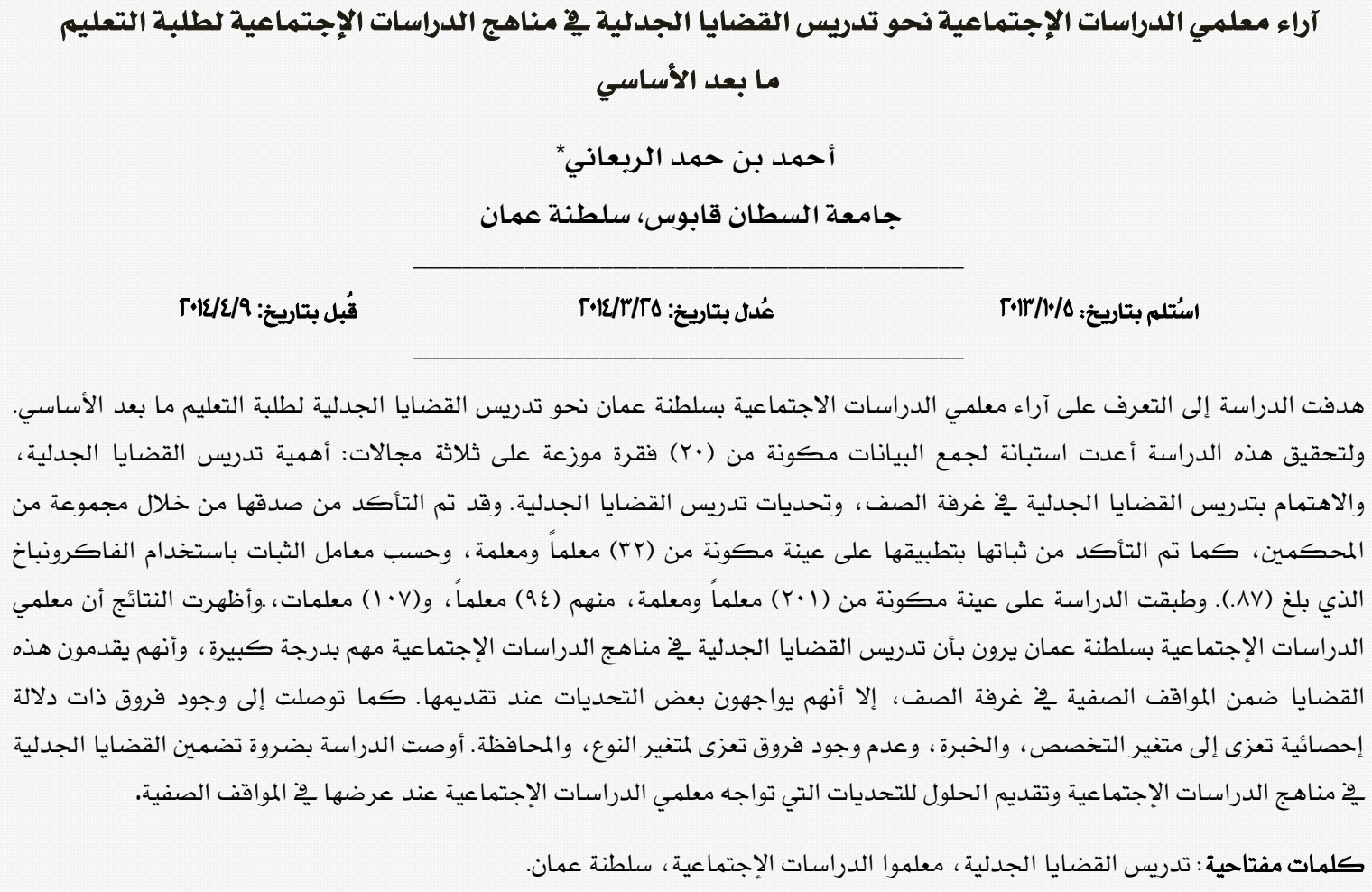

\title{
Omani's Social Studies Teachers' Opinions about Teaching Controversial Issues in Social Studies Curriculum for Post Basic Education Students
}

\author{
A hmad H. Al-Rabaani* \\ Sultan Qaboos University, Sultanate of Oman
}

The aim of the study as to investigate the opinion of Omani's social studies teachers' about teaching controversial issues in social studies curriculum for post basic education students. Data was gathered through a questionnaire consisting of (20) items divided into 3 areas: importance of teaching controversial issues, concernins about teaching controversial issues and challenges of teaching controversial issues. Validity of the questionnaire was examined by a panel of judges and reliability was obtained by administrate the questions to 32 social studies teachers. Cronbach Alpha was used. Data was collected from 201 social studies teachers, 94 were male and 107 were female. The results showed that social studies teachers highly belived about the importance of teaching controversial issues, they were teaching controversial issues in their classroom and they were facing some challenges in teaching controversial issues. There were significant differences due to teachers' specialization and experience while there were no significant differences due to gender or province.

Keyw ords: Teaching controversial issues, social studies teachers, Sultanate of Oman.

*arabaani@squ.edu.om 
سياسية معينة، وأخرى لا تزال تعانيمن عدم الاستقرار. وبالاضافة إلى إثكلية الاستقرار تشكل بعض القضايا تحديا

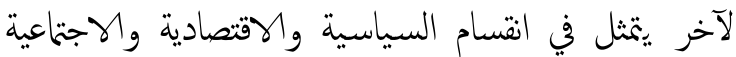
الذي قد يحول احيانا دون تنفيذ العديد من المشاريع التنموية. ومما يجعل تلك لقضايا تثكل خطرا" على الدولة والفرد هو

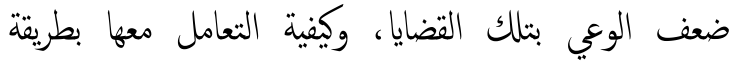
عقلانية تسهم في إيجاد الحلول بدلا من التطرف الذي قدائ

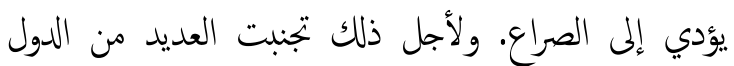

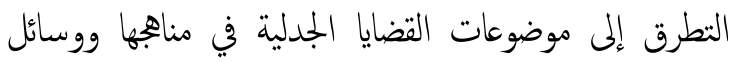

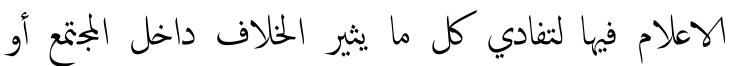
يوقض الفنته فيه، إلا أن الواقع المعايش في ظل المات انتشار الإعلام

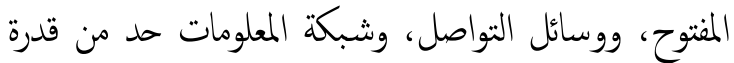

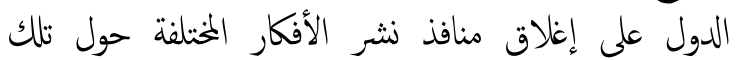

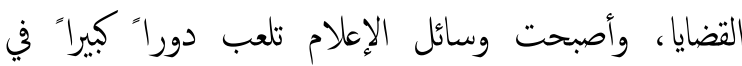
تشكيل الرأي العام الذي ربما يغاير توبهات الدولة.

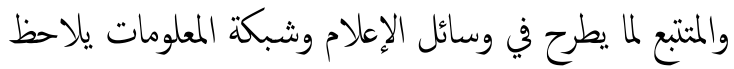
الأنتشار الواسع للآراء حول القضايا الجدلية المرتبطة بحياة الأفراد اليومية، وأن هناك عمليات استقطاب للفئات المختلفة

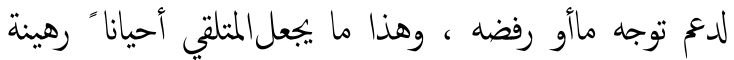

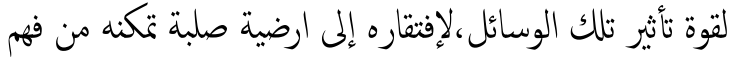

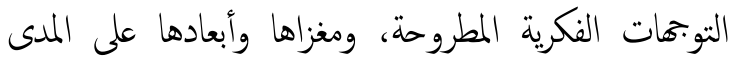

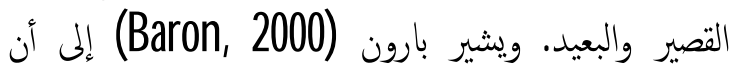
هناك الكثير من المعلومات التي تعرض للأفراد نتضمن الثمن اثباتات

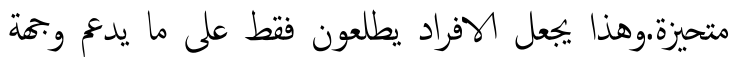
نظر معينة، ولا يطلعون على و.جات النظر التي تعارضها،

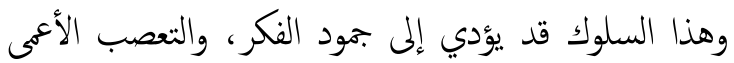

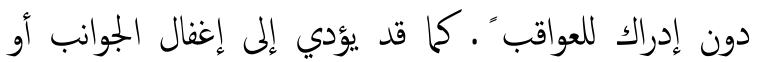
القواسم المشتركة (Taber \& Lodge, 2006).

ولزا ظهرت الآراء المؤيدة لتقديم القضايا الجدلية في المناجه

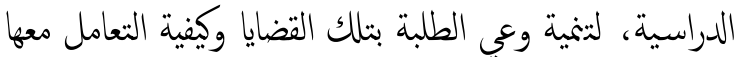

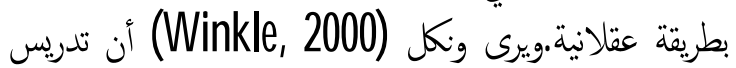
القضايا الجدلية يعد أساساء لبناء مواطن فاعل، ومن وبهة نظر

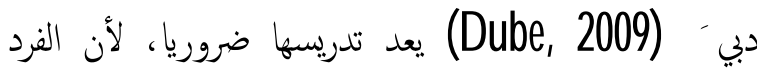
يعيش في عالم محير يشهد تحولات سياسية واجتاعية وتقافية

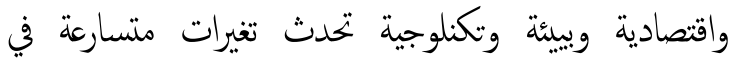

تعبر القضايا الجدلية عن الأحداث والتوجحات الفكرية والسياسية والاقتصادية والاجتاعية والثقافية والدينية التي

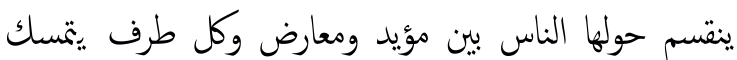
بوجهة نظره ويدافع عنها بقوة لاعتبارات كثيرة، وهذه الأحداث

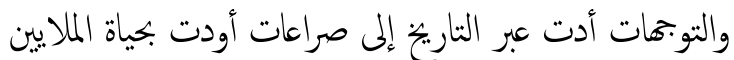

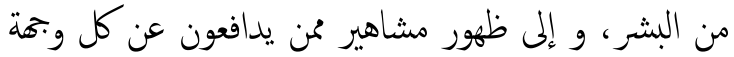
نظر، وظهور نظم سياسية، و اقتصادية، واجتاعية وثقافية كان لها تأثراتها الإيجابية والسلبية.

ويعرف ستاردلنج (Stradling, 1985) القضايا الجدلية بأنها

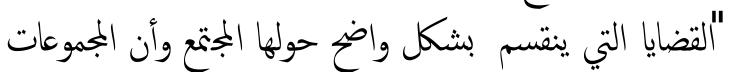

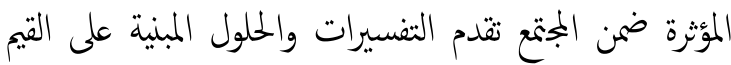

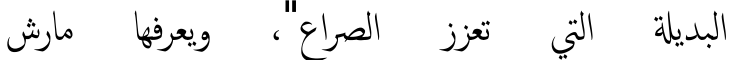
(Marsh,2005, 133)

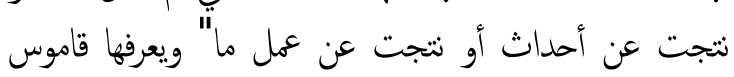

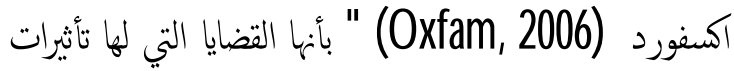

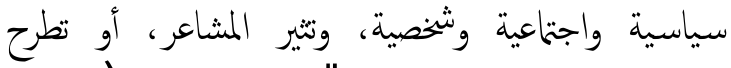

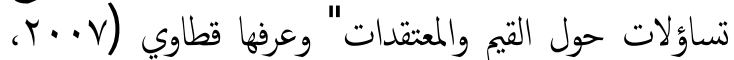

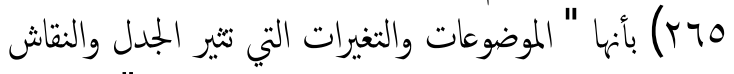

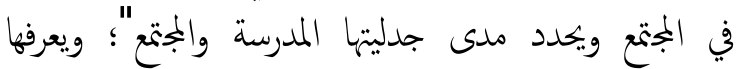

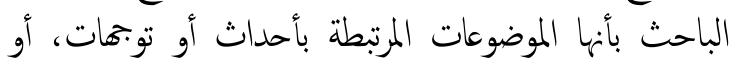

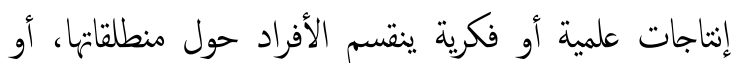

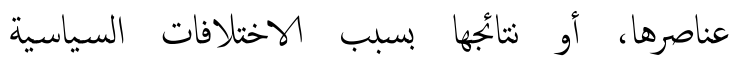
أوالاقتصادية، أوالاجتماعية أوالدينية أوالثقافية أوالعلمية ولماتل يتم التوصل إلى رآي مقبول من الجميع حولها. وتختلف درجة الجدل باختلاف الأسباب الكامنة وراء القضية

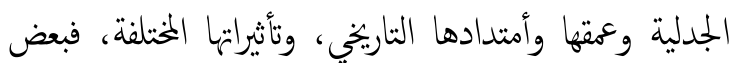

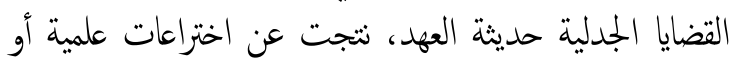

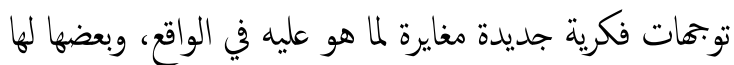
جذور تاريخية التي اصبحت بتعاقب السنين وما رافقها من

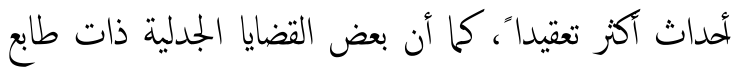
محلي، وبعضها ذات طابع إقليمي آو عالمي. وقد شكلت القضايا الجدلية تحديا للدول في عدة مجالات منها

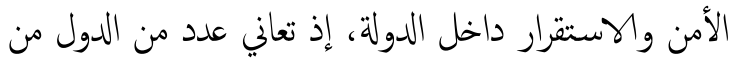

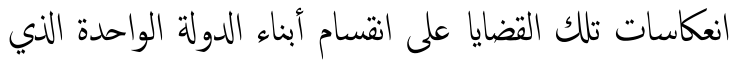

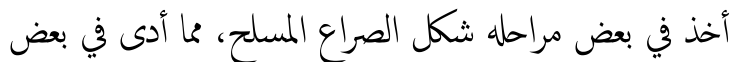
الدول إلى تقسيمها، و أوجد في بعضها آليات للوحدة ضمن نظم المراع 
لمم في المدارس، وعندما لا يتم الاهتمام بتعليمهم التحديات

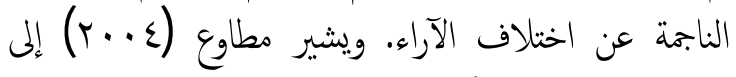
ضروة تنمية قدرات الأفراد للنعامل مع ما يقدم من قضايا مثيرة

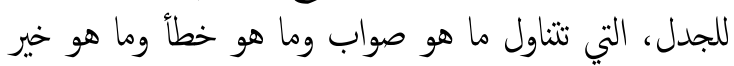

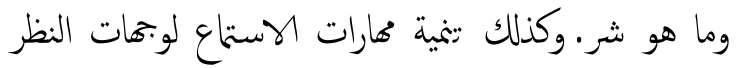

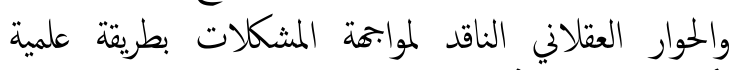

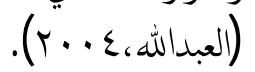

ونظرا" لاهية هذه القضايا فإنه من الضروري إفراد مساحة لها

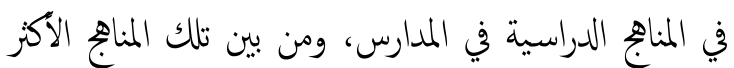
إمكانية لطرح هذه القضايا هي مادة الدراسات الاجتماعية لأنها

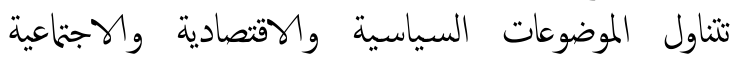

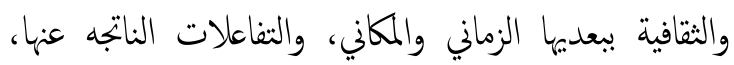

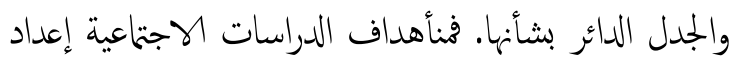

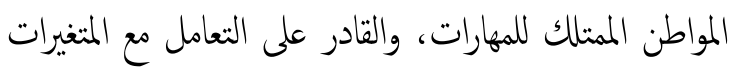

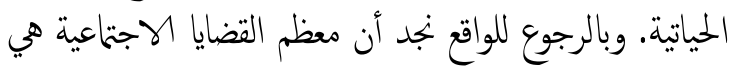

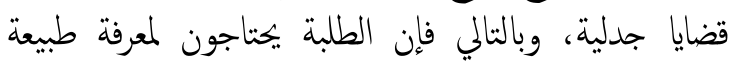
المثكلات الاجتماعية التي تؤثر على حياتهم كواطنين فاعلين المين

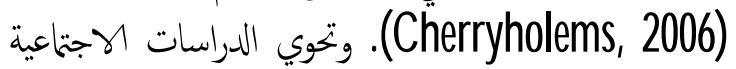

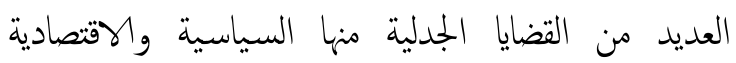

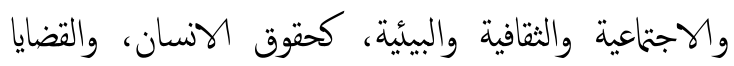

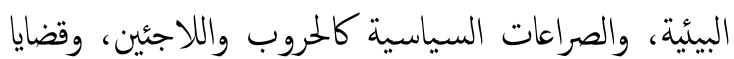

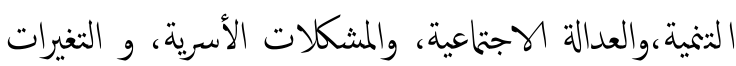

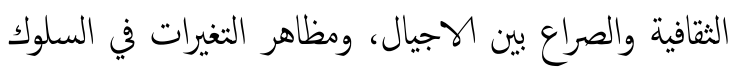

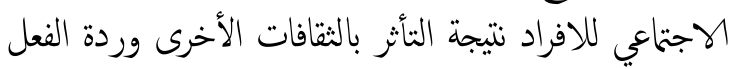

حولها.

ويرى بارك (Parker, 2001) أن معلم الدراسات الاجتماعية

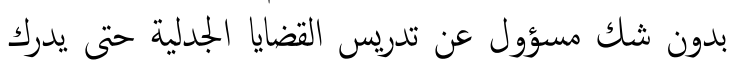

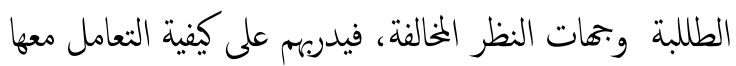

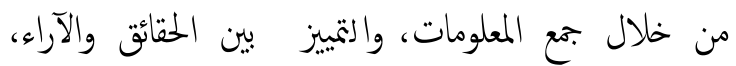
والخروج باستنناجات ويرى البعض المعلومات ولمئ على معلم الدراسات

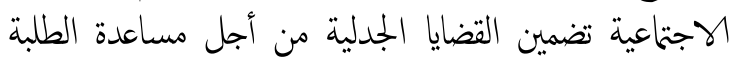

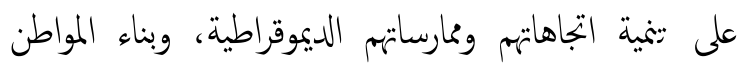
الفعال، (Patrick \& Vantz, 2001) وكذلك تصحيح

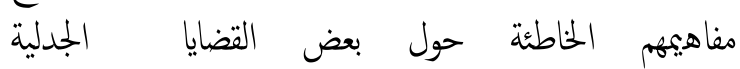

(Hess, 2001)

ويمكن للدراسات الاجتماعية تقديم هذه القضايا مع مراعاة

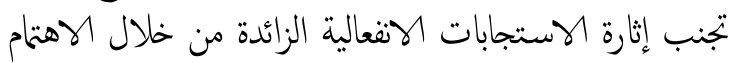

المنظومة القيمية، وحتى يتعايش الفرد مع هذه التغيرات لابد وأن ينطلق من أرضية صلبة.

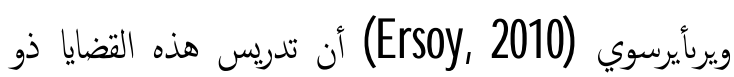

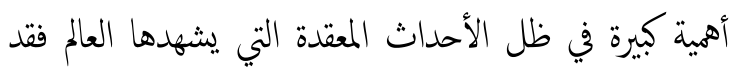

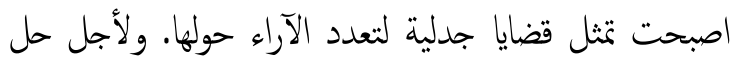

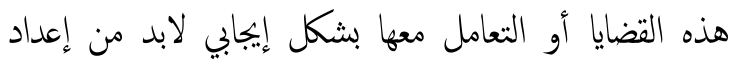

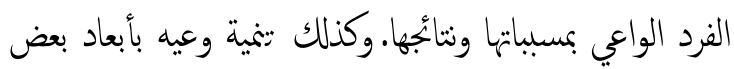

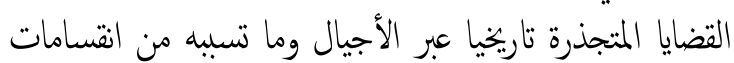
كيرة داخل الجمتع (Crumley, 2002). وعليه كان لابد للتربية أن تسعى إلى إعداد أجيال مدركه لما يقدم

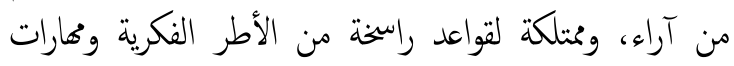
التفكير التي تمكها من التعامل مع تلك الآراء بطريقة واعية. ويرى ويو ومارتن

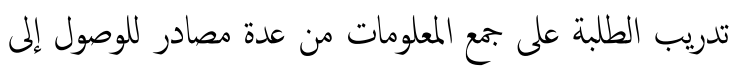

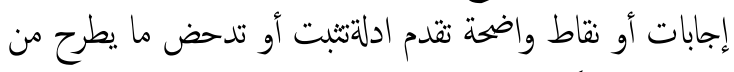

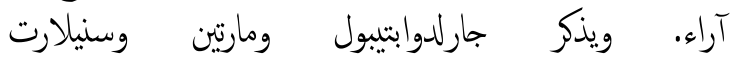
، (Gallard, A biteboul, Marian \& Senellart, 2010) أن على المعلم توجيه الطلبة لعرض المعلومات التي جمعوها

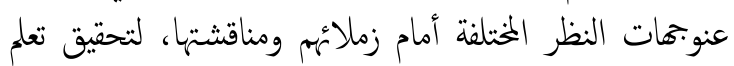

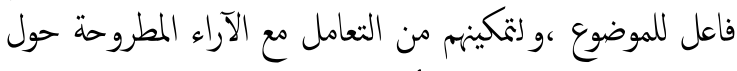

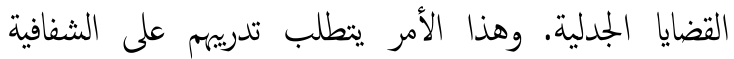

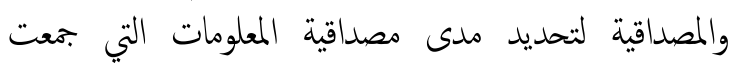
.(Suh, Chi, Kittur \& Pendleton, 2008) إن تقديم القضايا الجدليةذا أهمية كيرة للطلبة، لتكينهم من التفاعل معها، ولاسيا تلك القضايا المرتبطة بحياتهم اليومية

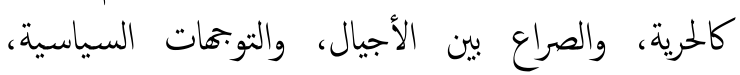
والاقتصادية، والحتماعية، والثقافية، وقضايا التنمية داخل والح الجيت (Brum, Bouldin, \& White, 2000) ويشير فريرر (Freirer, 1998) إلى أن عدم الهمتام بالقضايا الجدلية في المناجج الدراسية سيؤدي ببساطة إلى إعادة إنناج

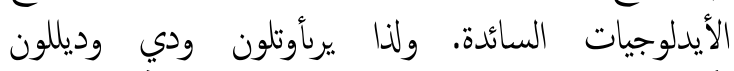
(Oulton, Day, Dillon \& Grace, 2004)

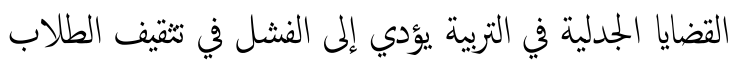

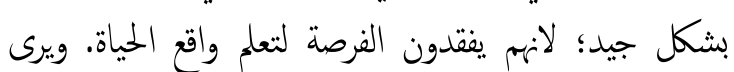

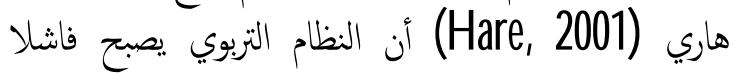

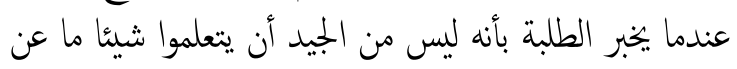

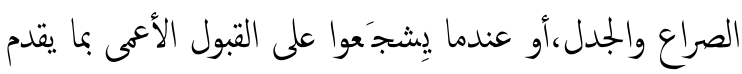




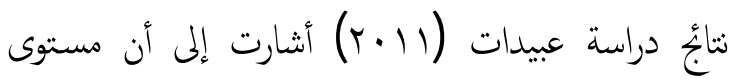
معرفة معلمي التاريخ بالقضايا الجدلية دون المستوى المقبول المارن تربويا.

كما أهتمت بعض الدراسات بمعرفة اتجاهات المعلمين نحو المبات

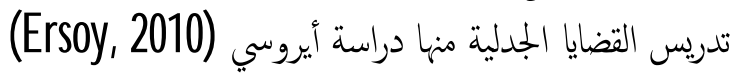

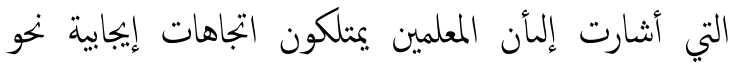

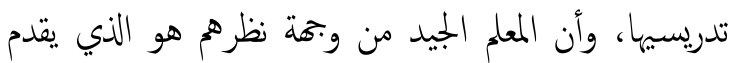

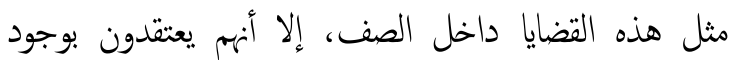
صعوبات عند عرضها بسبب قلة معلوماتهم عن تلك الته القضايا .

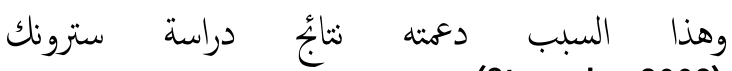
(Stronck, 2002) القضايا الجدلية لضعف خلفياتهم المعرفية بها، وضعف عهاراتهن

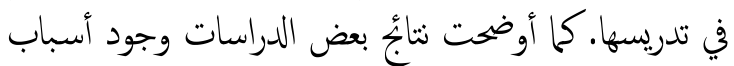

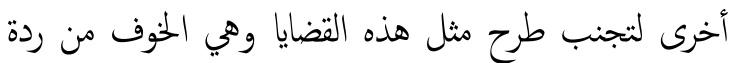
فعل الجمتع السلبي حيال طرحما، وتبعاتها القانونية والسياسية .(Asimeng \& Boahene, 2007; O ulton et al., 2004)

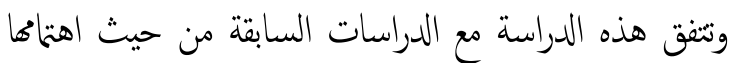

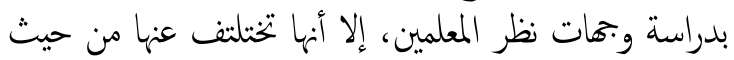

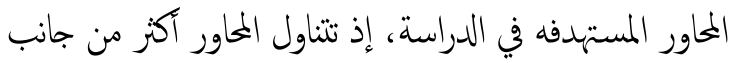

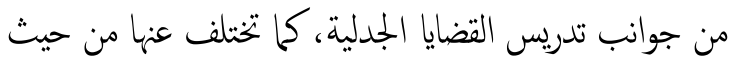
الجمتع المستهدف إذ طبقت هذه الدراسة في سلطنة عمان.

\section{مشكلة الدراسة}

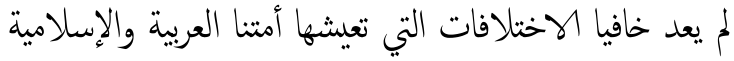

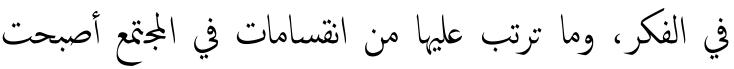

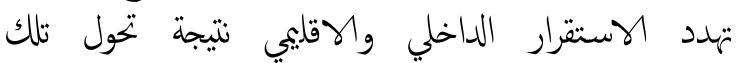

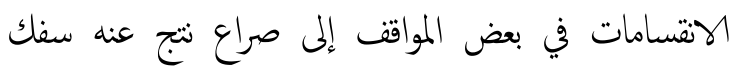

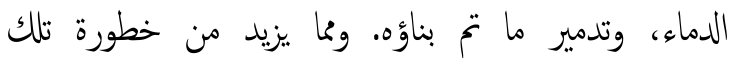

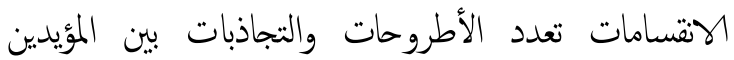

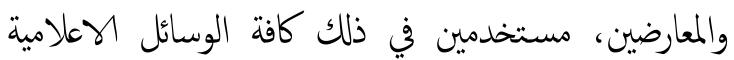

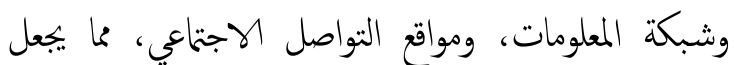

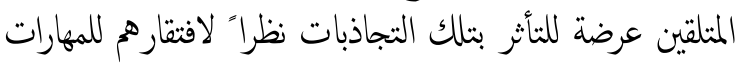

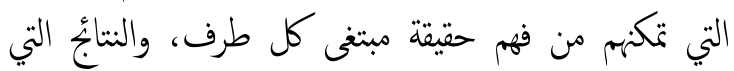

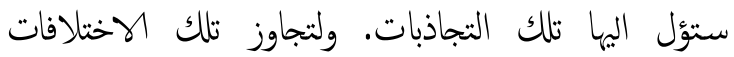

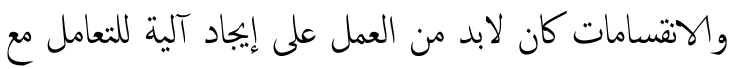

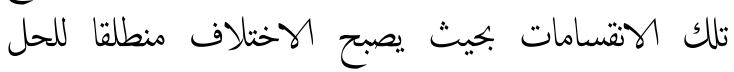

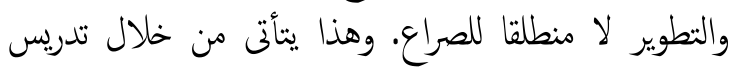

بلمناطق الهنة (Safe Zones) عند تقديم القضايا الجدلية

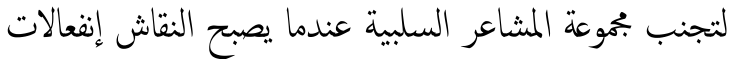
غير مرغوبه، وكذلك إكساب الطلبة مارات النعامل مع القضايا

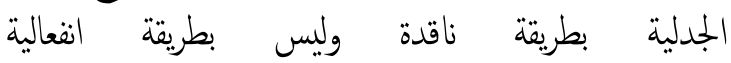
(Ballagh \& Sheppard, 2004) (Oulton et al, 2004)

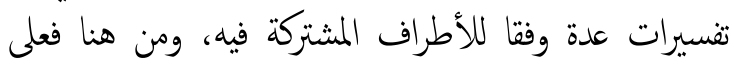
المعلمين تقديم أحكام موضوعية حول الحقائق المرتبطة بكل المكل

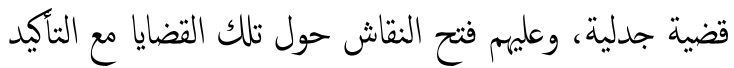
على منح الطلبة فرصة الوصول إلى قناعات حولها.

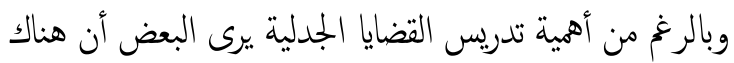

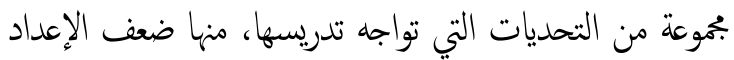

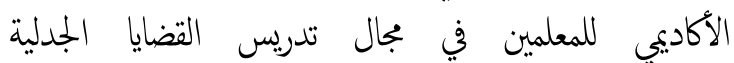

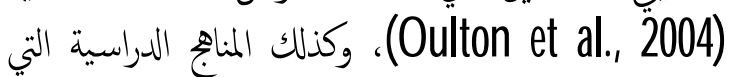

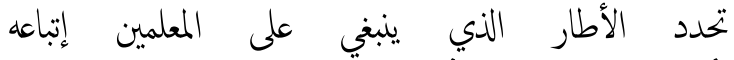

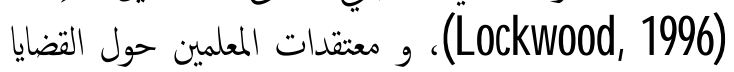
الجدلية (Brookfield \& Preskill, 2005)، و و إنشكالية الوصول إلى المعلومات اللازمة حول هلماتل هذه القضايا

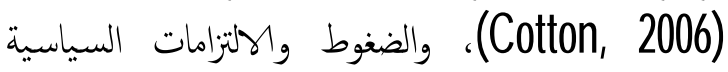
(Kincheloe, 2005) ) والتخوف من الإنتقادات من قبل النيل

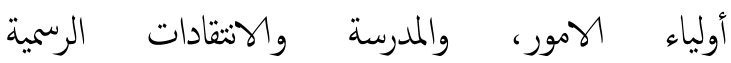

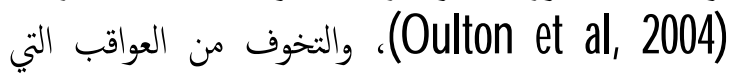

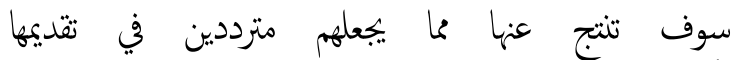
Zoric, Äst, Lang,Vamvalis, Weber, \& Wong, )

(2004

وقد أهتمت بعض الدراسات بمعرفةوبهات نظر التربويين نحو تدريس القضايا الجدليةومن بينها دراسة (DUbe, 2009)

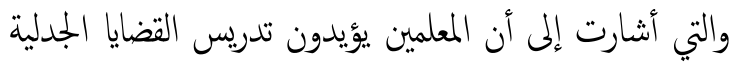

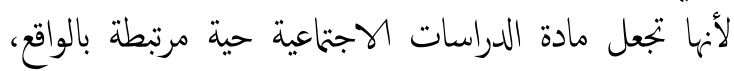

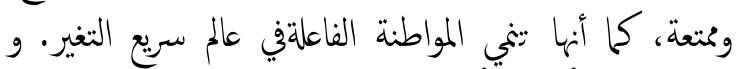

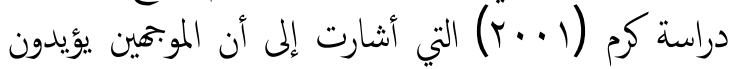

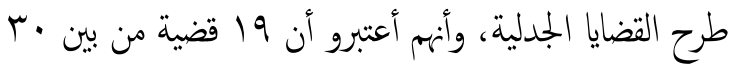

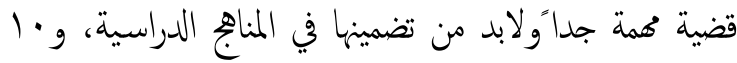

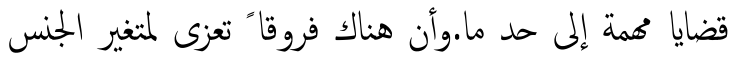

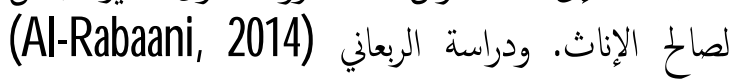

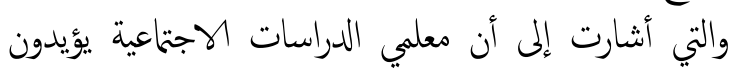
طرح القضايا الجدلية في مناجه الدراسات الاجتاعية، إلا ان ان النتاعية 
- الصعوبات التي تواجه معلمي الدراسات الاجتاعية في

تدريس القضايا الجدلية.

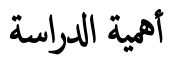

- التعرف على موقف معلمي الدراسات الاجتماعية بسلطنة عمان بشأن تدريس القضايا الجدلية، ومدى ماتف توافقه مع التوبحات العالمية في تدريس هذه القضايا. - التعرف على التحديات التي تواجه معلمي الدراسات

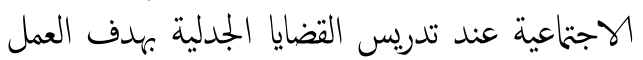
على الحد من تلك التحديات وتعزيز تدريسها. - إلقاء الضوء على مدى إدراك معلمى الدراسات

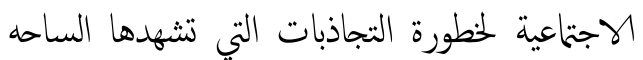

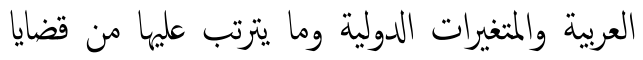
جدلية ساخنة تلقي بظلالها على العملية التعليمية بشكل عام وعلى الطلبة بشكل خاص.

إثراء الأدب التربوي في موضوع القضايا الجدلية لندرةالدراسات في هذه الموضوع بسلطنة عمان.

\section{تعريف المصطلحات}

يعرف ستاردلنج (Stradling, 1985.9) القضايا الجدلية

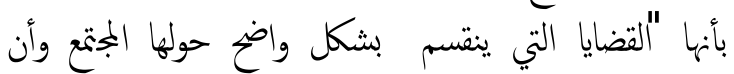
المجموعات المؤثرة ضمن الجمتمع تقدم النفسيرات والحلول المبني المبنية على القيم البديلة التي تعزز الصراع".

التعريف الاجرائيبأنها الموضوعات المرتبطة بأحداث أو

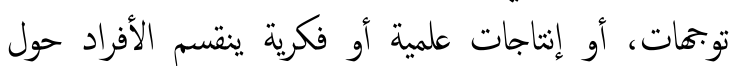

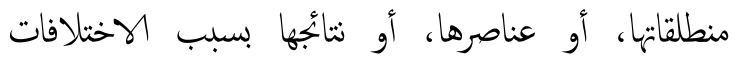

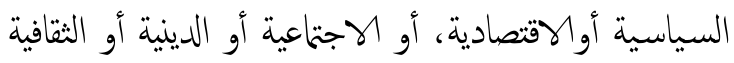

أو العلمية ولم يتم التوصل إلى رآي مقبول من الجميع حولها. آراء معلمي الدراسات الاجتاعية' استجابة معلمي الدراسات الاجتماعية على فقرات الاستبانه حول اهمية تدريس القضايا

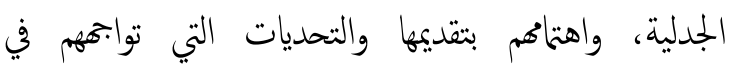

تدريسها.

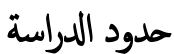

-

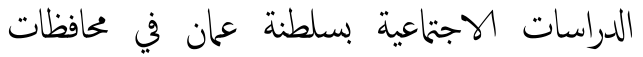
مسقط، والداخلية، والباطنة جنوب، والشرقية شهال.
القضايا الجدلية في المناجه الدراسية وهذا ما أكد عليه الأدب التربوي (Bulton, Brum, Bouldin, \& White, 2000 .(Freirer, 1998 Dillon \& Grace, 2004 وقد سعت الأنظمة التربوية إلى إدخال بعض القضايا الجدلية

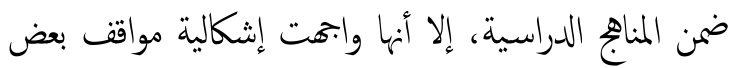

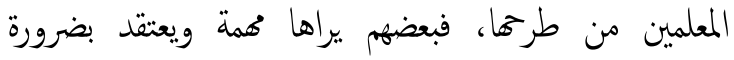

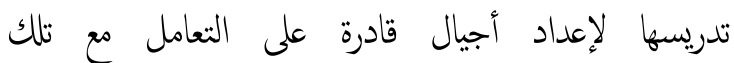
القضايابعقلانية (DUbe, 2009; Ersoy, 2010)، وآخرون

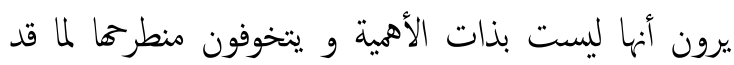
تسبه من مشكلات سلبية على الطلبة والمعلمين أنفسهم .(Asimeng \& Boahene,2007; O ulton et al, 2004) وهذا النباين في الآراء يعد إثكالية كبيرة بالنسبة للداعمين

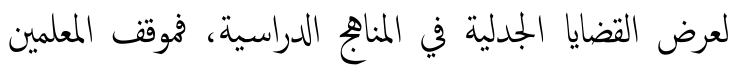

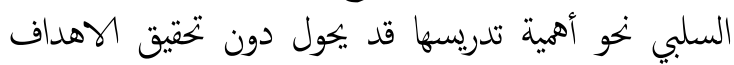

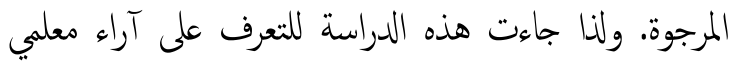
الدراسات الاجتاعية بسلطنة عمان حول تدريس الماته القضايا

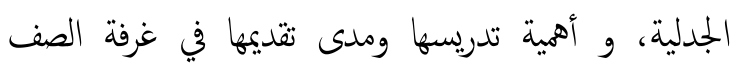
والتحديات التي توابهمه عند تقديمها.

وتسعى الدراسة الحالية إلى الاجابة عن الاسئلة الاتية:

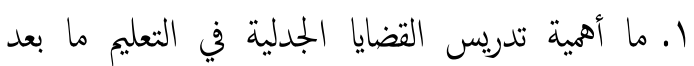

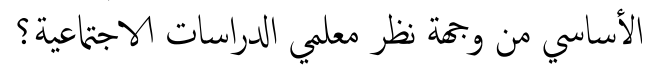
r. ما مدى اهتمام معلمي الدراسات الاجتماعية في التعليم

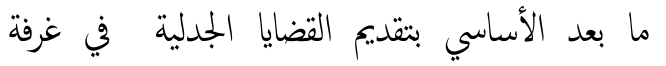
الصف؟ - مإ بعد r. ما التحديات التي يواجهها معلموا الدراسات الاجتماعية

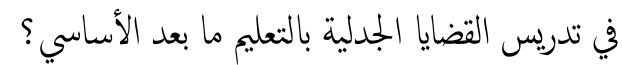
ع. هل تختلف آراء معلمي الدراسات الاجتاعية نحو

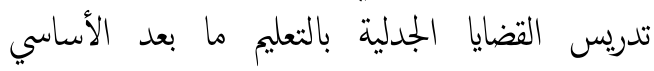
باختلاف النوع، والتخصص، والخبرة، والمحافظة؟

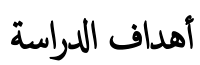
تهدف هذه الدراسة إلى التعرف على : - آراء معلمي الدراسات الاجتماعية بسلطنة عمان نحو تدريس القضايا الجدلية 
Cotton, 2006), Ersoy, 2010

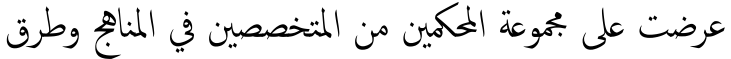

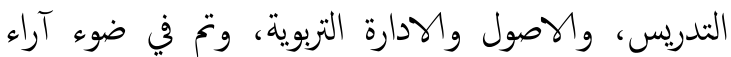
المحكين حذفت فقرين، لتصبح الصورة الهنائية للاستبانة

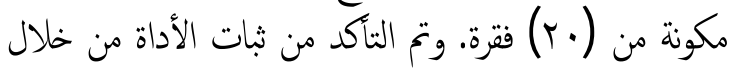

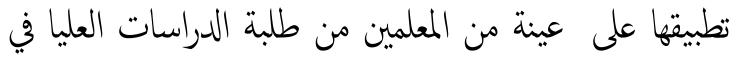

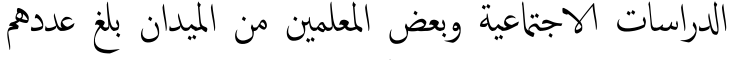

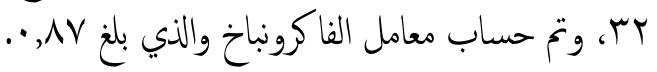

\section{المعالجة الاحصائية}

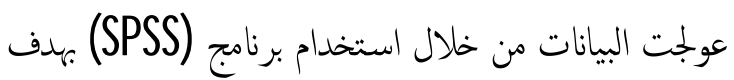

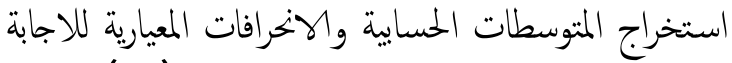
عن السؤال الأول، والثاني والثالث، واختبار ( ت) للإجابة الماتية

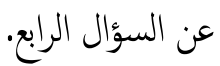

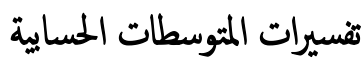
تم تنسير المتوسطات الحسابية باستخدام التدريج الذي يعرضه جدول )

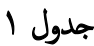

معاني الدرجات المستخرجة من المتوسطات

\begin{tabular}{|c|c|c|c|}
\hline التحديات & المدال المضايلية & القضايا الجدلية & المتوسط الحسابي \\
\hline كبيرة جدا & دائما & كبيرة جدا & $0-\varepsilon, 0$ \\
\hline كبيرة & غالبا & كبيرة & $\varepsilon, \varepsilon q-r, 0$ \\
\hline متوسطة & احيانا & متوسطة & $r, \varepsilon q-r, 0$ \\
\hline قليلة & نادرا & قليلة & $r, \varepsilon q-1,0$ \\
\hline قليلة جدا & لا اعرضها & قليلة جدا & $1,29-1$ \\
\hline
\end{tabular}

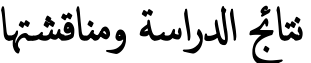

السؤال الأول: ما أهية تدريس القضايا الجدلية في التعليم ما بعد الاساسي من وبحة نظر معلمي الدراسات الاجتماعية؟ وللإجابة عن هذا السؤال تم حساب المتوسطات المسابت المسابية والانحرافات المعيارية لققرات أهمية تدريس القضايا الجدلية

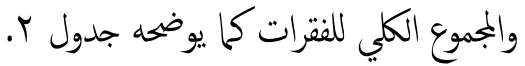

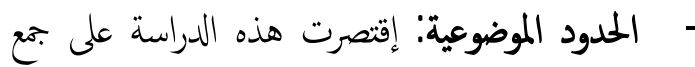

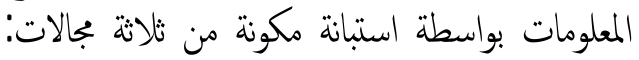

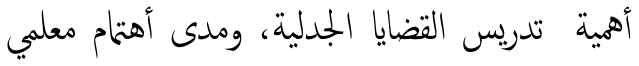

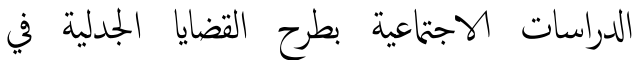
المواقف الصفية، والتحديات التي توابتهم في تدريس الميس

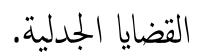

- الحدود الزمانية تم تطبيق الدراسة في عامَّا •r.

\section{الطريقة والاجراءات}

انبعت الدراسة المنهج الوصفي، لكونه الأنسب في دراسة آراء

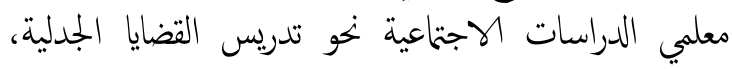
والني يعتمد على جع البيانات، وتحليلها ووصفها. جمقع الدراسة وعينه تكون مجتع الدراسة من جميع معلمي الدراسات الاجتماعية

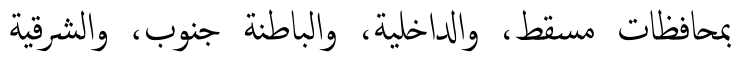

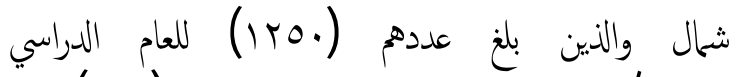

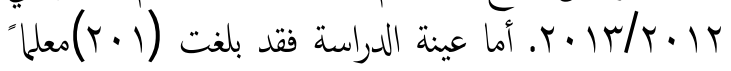

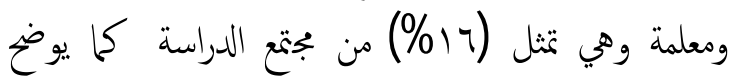
الجدول الاتي.

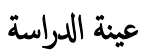

\begin{tabular}{|c|c|c|}
\hline النسبة & العدد & النوع \\
\hline$\sum 7.1$ & $9 \varepsilon$ & ذوكر \\
\hline r,or & $1 . v$ & إناث \\
\hline $1 \ldots$ & r. 1 & الجموع \\
\hline
\end{tabular}

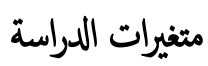

المتغير المستقل: النوع، والتخصص، والمبرة، والمحافظة.

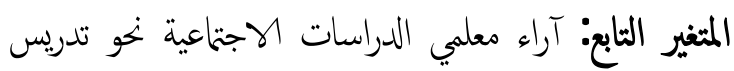

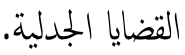

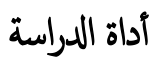

إستخدم في هذه الدراسة استبانة ذات تدرج خحاسي، تكونت

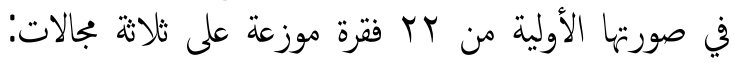

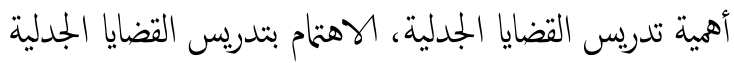

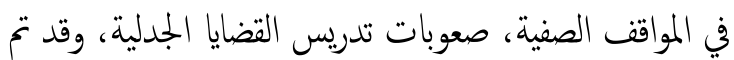
بناء الاستبانة في ضوء الادب التربوي (Zoric et al, ) 2004; Oulton et al, 2004; Cherryholems, 2006; 


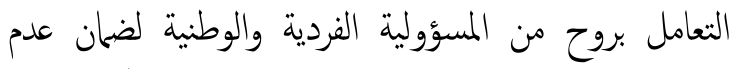

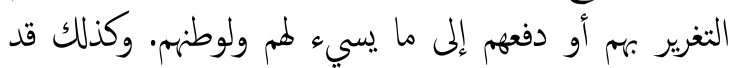

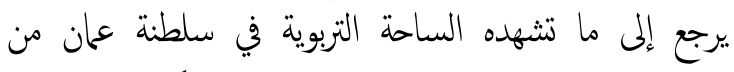

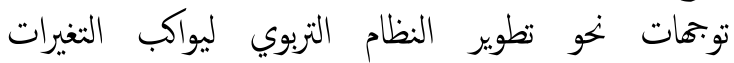
والتحديات التي تشهرها السلطنة والحاجة إلى بناء مواطن النيات

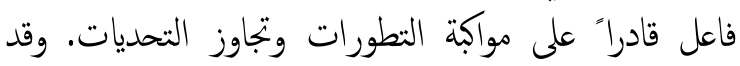

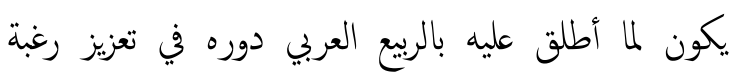

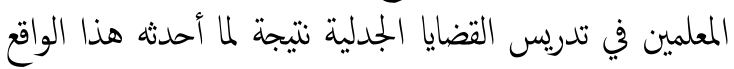

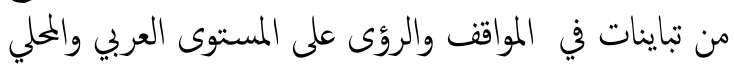

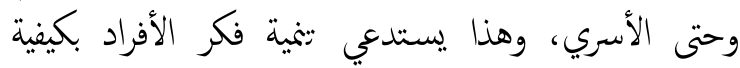

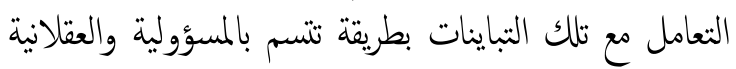

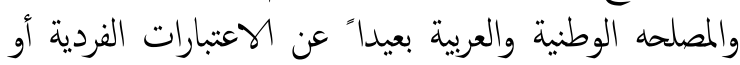

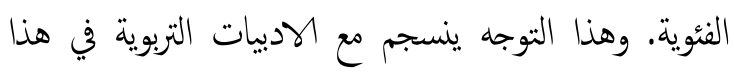

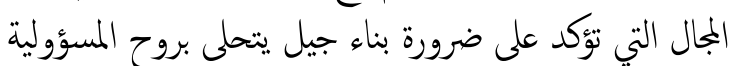
(Winkle, 2000; Dube, 2009; Ersoy", 2010)

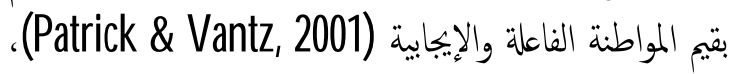
وقادرا" على التميز بين الحقائق والآراء المطروحة عبر الفضاء المفتوح (Parker, 2001) ، وقادرا" على تصحيح المفاهيم الخاطئة التي يتم الترويك لها (Hess, 2001).

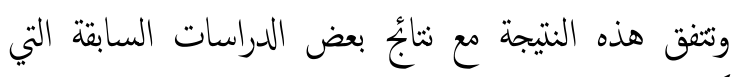

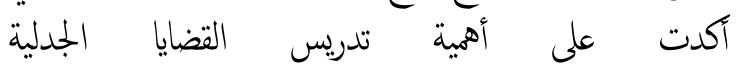
(DUbe, 2009; Ersoy, 2010)

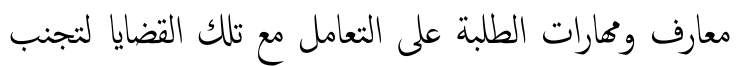

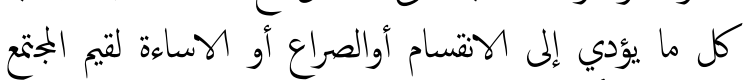
Crumley, 2002; WU \& Martin, 2007; ) ومقدراته (Gallard, et al, 2010; Ersoy, 2010; نتيجة هذه الدراسة والدراسات السابقة ييين لنا أن المعلمين الماني

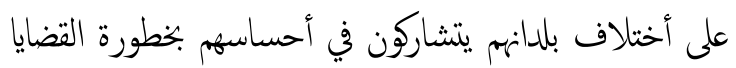

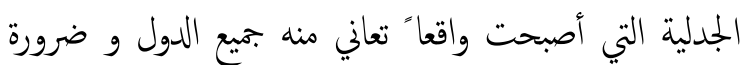

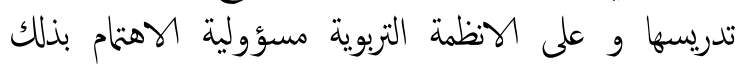
لتنشئة الأجيال القادرة على التعامل مع ذلك الواقع.

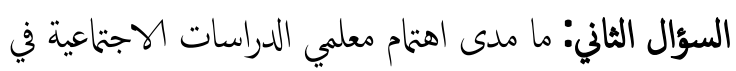

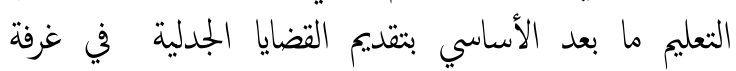

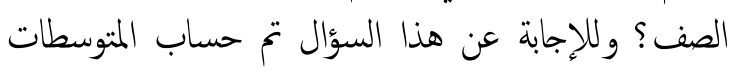

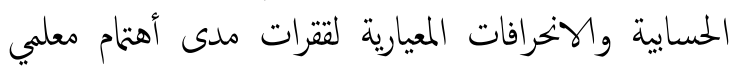

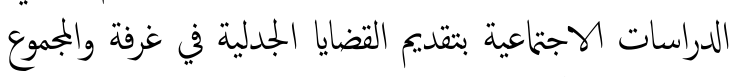

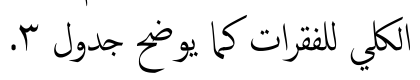

\begin{tabular}{|c|c|c|c|}
\hline \multicolumn{4}{|c|}{ 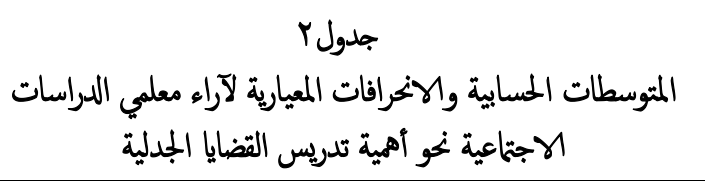 } \\
\hline المعياري & المتوسط المسابي & العينة & أهمية تدريس القضايا الجدلية \\
\hline & & & يسي تنمية' تدريس القضايا الجدلية \\
\hline,$q \sum r$ & $r, 91$ & $r \cdot 1$ & معارف الطلبة بهذه القضايا، \\
\hline $1, \cdot 7 \pi$ & $r, q$. & 191 & الطلبة بهذه القضايا، و ومعتقدات وقيم \\
\hline $1, \cdot r$. & $r, \wedge r$ & $r \cdot 1$ & التعامل مع مواقق مرتبطة الإيجابي للطلبة عند \\
\hline $1, \cdot r$. & r, vo & $r \cdot 1$ & في مثل هذه القضايا، الطلبة لإشكالية التحزز \\
\hline,$\wedge \backslash \Lambda$ & $r, \pi r$ & $r \cdot 1$ & قآدراء والاختلافات. الطلبة على تثييم \\
\hline 1,11 & $r, 09$ & $r \cdot 1$ & 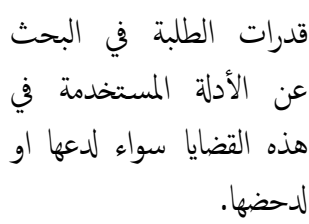 \\
\hline 1097 & $r, v ч$ & $r \cdot 1$ & المتوسط العام \\
\hline
\end{tabular}

تشير النتاجُ في جدول r إلى أن معلمي الدراسات الاجتماعية

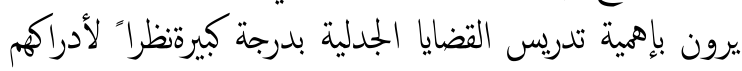

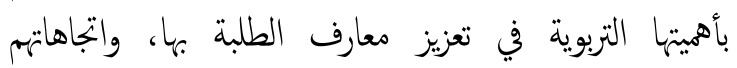

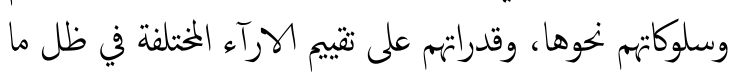

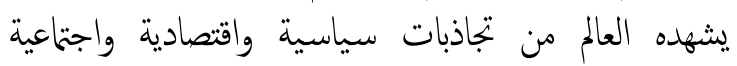

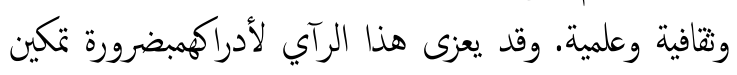

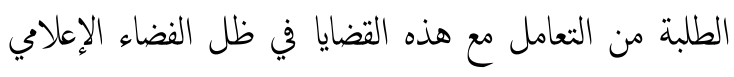

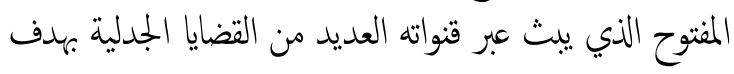

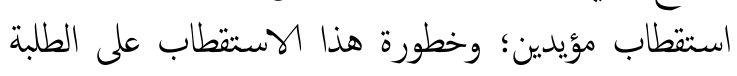

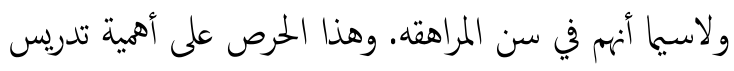

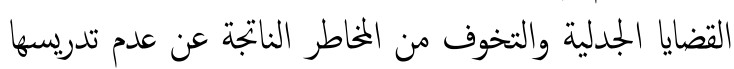

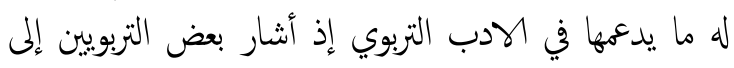
خطورة ما يبث عبر وسائل الإعلام وشبكات التار التواصل

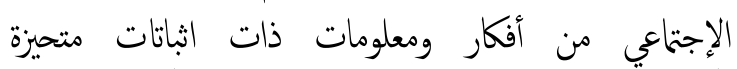
(Baron, 2000; Taber \& Lodge, 2006) وبالإضافة إلى ذلك فريما يعزى ذلك الرأي إلى أحساس

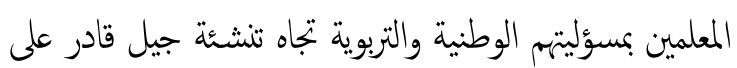




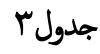

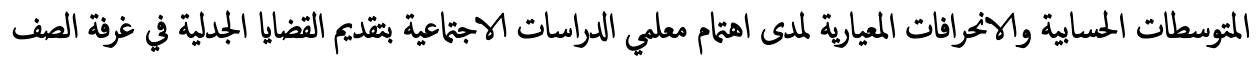

\begin{tabular}{|c|c|c|c|}
\hline الانحراف المعياري & 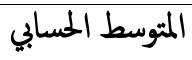 & 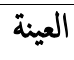 & الاهتام بتقديم القضايا الجدلية \\
\hline $1, r 91$ & $r, q 1$ & $r \cdot 1$ & أعرض بعض القضايا الجدلية في بعض الدروس. \\
\hline $1, \cdot 9 \mathrm{~V}$ & $r, V \varepsilon$ & r. & أثرك الطلبة في طرح بعض القضايا الجدلية في الصف. \\
\hline l, 1Nr & $r, V V$ & $r \cdot 1$ & أثشجع الطلبة على جمع المعلومات حول بعض القضايا الجدلية. \\
\hline $1, r \uparrow \Lambda$ & $r, 70$ & $r \cdot 1$ & أوضح الفرق بين القضايا الهتيادية والقضايا الجدلية. \\
\hline $1, r \varepsilon \wedge$ & $r, \wedge 1$ & $r \cdot 1$ & ومناقشتها. من الطلبة جمع بعض رسوم الكاركتير حول بعض القضايا الجدلية \\
\hline l, rAT & $r, \varepsilon r$ & $r \cdot 1$ & أناقش مع الطلبة بعض المقالات التي تطرح قضايا جدلية عبر الوسائل المختلفة. \\
\hline ,AVוqA & $r, 00$ & r. & المتوسط العام \\
\hline
\end{tabular}

الإعلاي المفتوح، وجيل هنفتح على العالم الخارجي ولديه

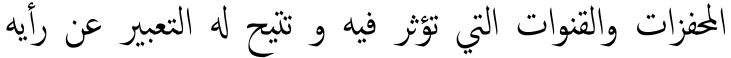

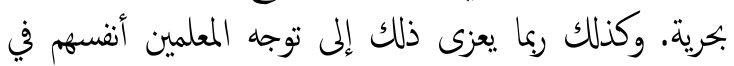

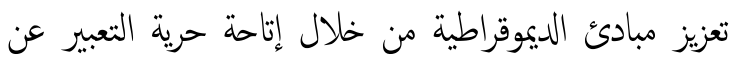
الآراء حول بعض التضايا الجدلية التي تشغل الرأي المحلي والاقييم.

(Ersoy, 2010) وتنفق نتأُج هذه الدراسة مع نتيجة دراسئ

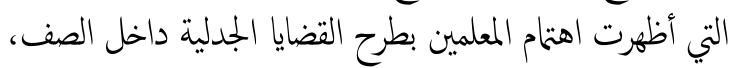

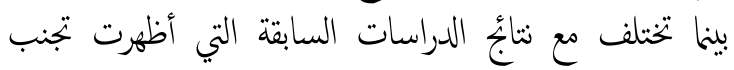

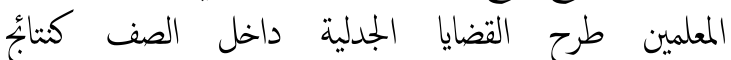
(Ásimeng \& Boahene, 2007; Oulton et al, دراسة

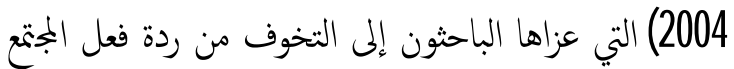

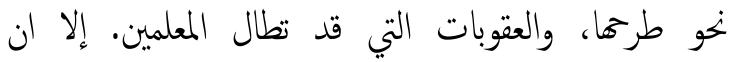

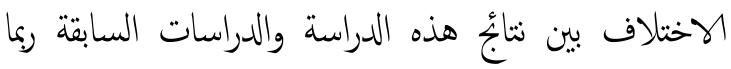

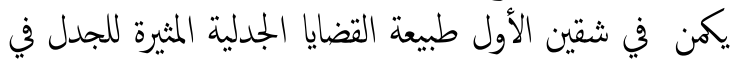

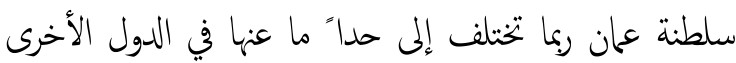
فبعض القضايا التي تناولتها الدراسات السابقة هي قضايا

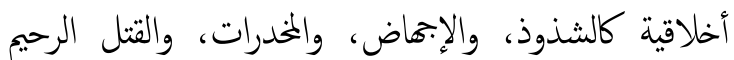

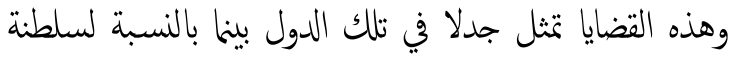

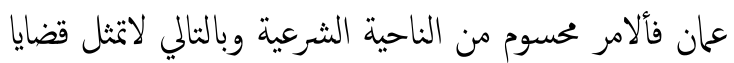

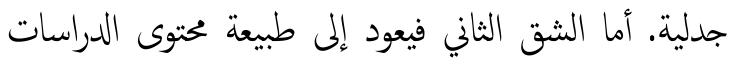

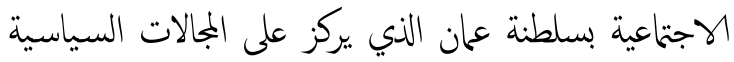

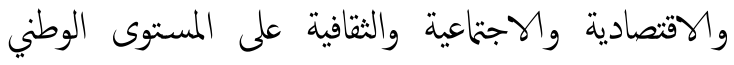
والعربي وهذه القضايا تطرح في وسائل الإعلام المحلية والعربية الماعنية ومواقع التواصل الاجتاعي ما قد قد يشجع المعلمين على طرحما

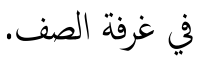

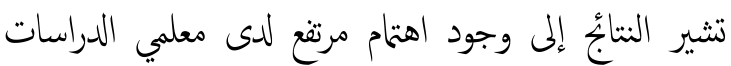

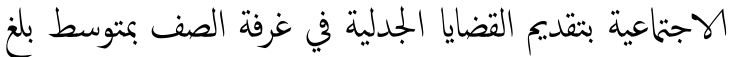

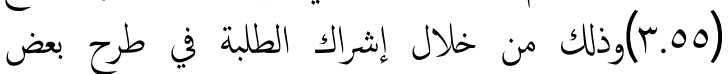

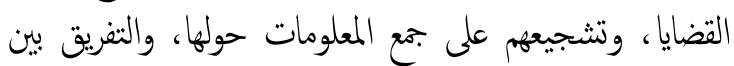

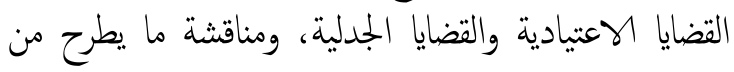

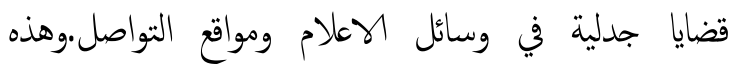
المارسات الندريسية تبين أن معلمي الدراسات الاجتماعية الماتية

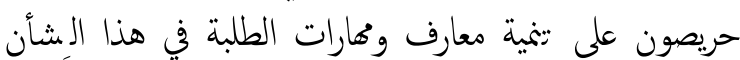
WU \& Martin, 2007 ; SUh et al, 2008; Gallard )

. (et al, 2010

وتدل هذه النتيجة على إدراك هؤلاء المعلمين لدور الدراسات

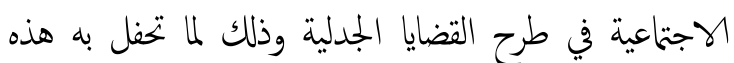
المادة من قضايا جدلية سياسية واقتصاديةواجتاعيةوثقافية المانية Crumley, 2002; Oulton et al, 2004; I (Cherryholems, 2006; Ersoy, 2010

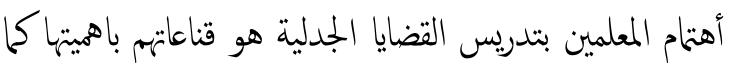

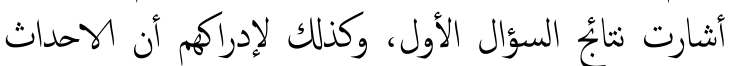

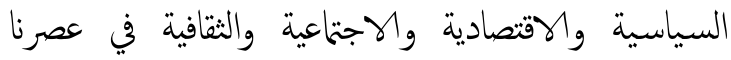

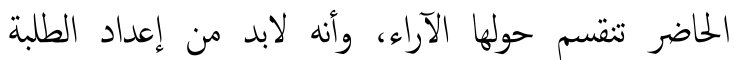

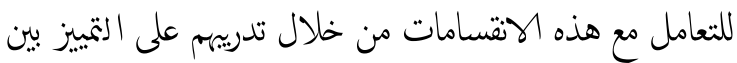

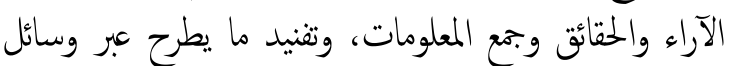

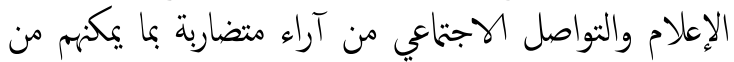
التعامل الإيجابي معها.

وقد يكون اهتمام المعلمين بتقديم هذه القضايا نابعا" من إدراكهم

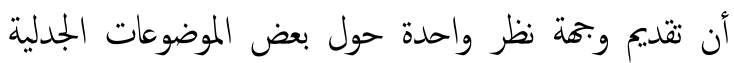
المضمنة في الكتب الدراسية لم يعد مجديا" في ظل الفضاء 
النتيجة تتفق مع النتائُ التي توصلت إليها دراسة .(Preskill, 2005)

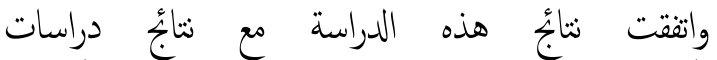
(Stronck, 2002; Oulton et al., 2004) أشارت إلى ضعف محارات المعلمين في مجال تدريس القضايا

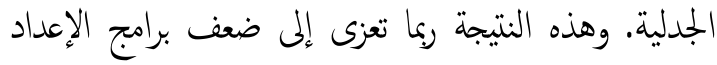

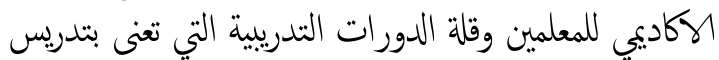

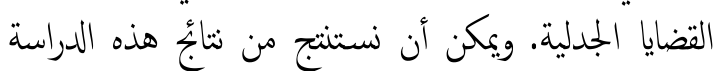

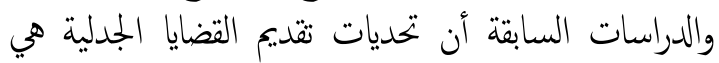

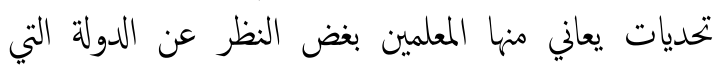

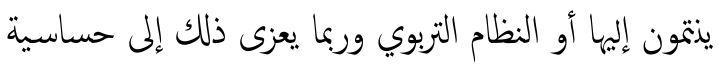

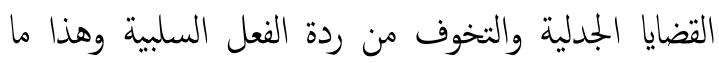

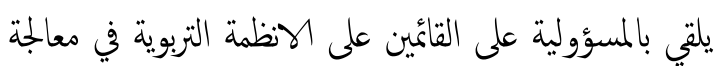
تلك التحديات.

السؤال الرابع: هل تختلف آراء معلمي الدراسات الاجتماعية

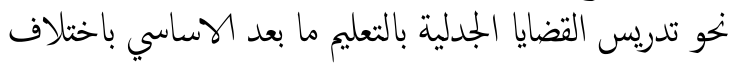

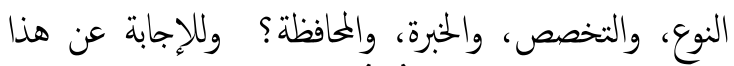

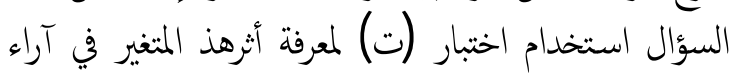
معلمي الدراسات الاجتماعية نحو تدريس القضايا الجدلية. وقد أشارت النتائُ إلى عدم وجود فروق ذات دلاتلة الماتل

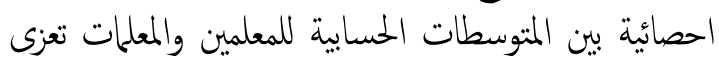

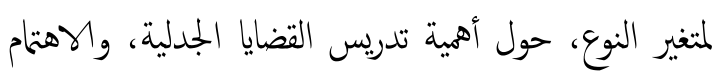

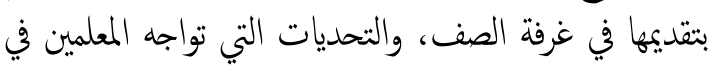

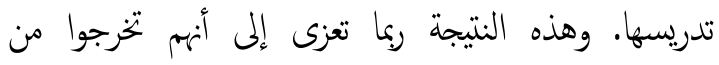

السؤال الثالث' ما التحديات التي يوابهها معلمو الدراسات

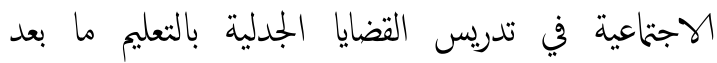

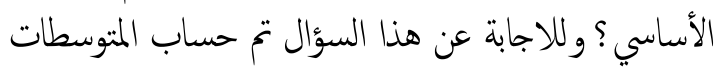

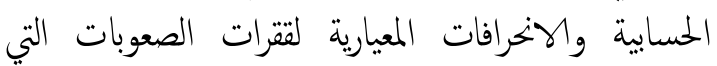
يوابجها معلمو الدراسات الاجتاعية في تدريس القضايات

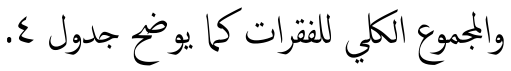

تشير النتأُج في جدول ع إلى وجود تحديات تحول دون

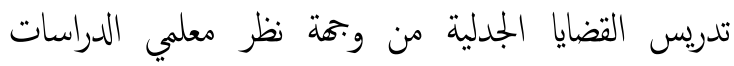

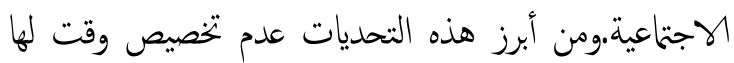

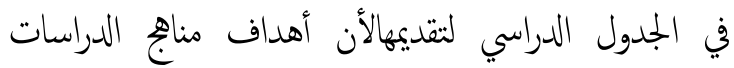

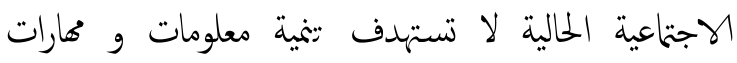

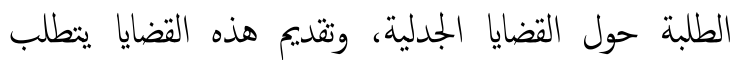

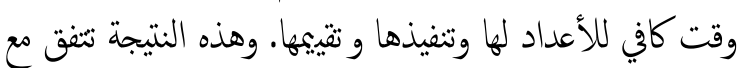

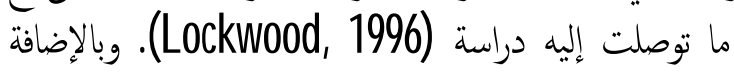
لتحدي الوقت يبرز تحدي أخر وهو التخوف من التأثيرات السلبية على الطلبة الناتج عن عدم تضمين كتب المتب الدراسات

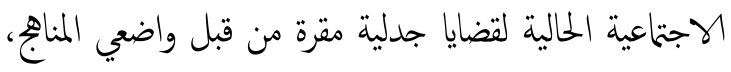

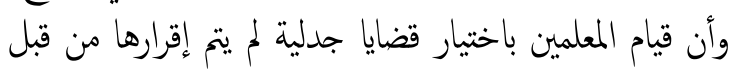

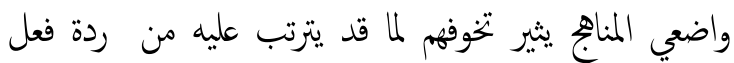
سلبية من قبل واضعي المناهج أو أدارة المدرسة أو أوليا

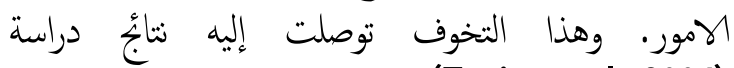

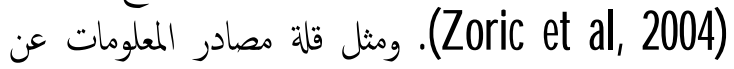

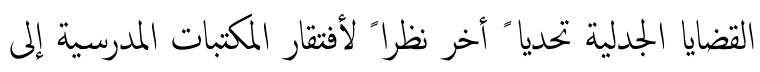

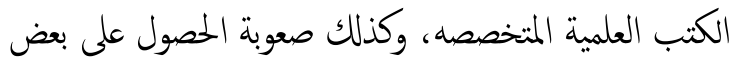

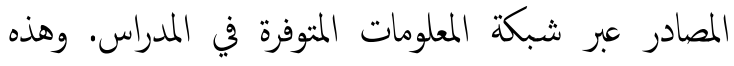

\section{جدولع}

المتوسطات الحسابية والانحرافات المعيارية للتحديات التي يواجهها معلمو الدراسات الاجتاعية في تدرس القضايا الجدلية

\begin{tabular}{|c|c|c|c|}
\hline المعياري & المتوسطي & العينة & صعوبات تدريس القضايا الجدلية القية \\
\hline $1, r \cdot$ & $r, \varepsilon \cdot$ & $r \cdot 1$ & حساسية بعض القضايا الجدلية من النواحي السياسية والاجتاعية والثقافية. \\
\hline $1, r V$ & $r, \varepsilon\rceil$ & $r \cdot 1$ & المنجج المدرسي يحد من قدرتي على طرح مثل هذه القضايا. \\
\hline $1, \varepsilon r$ & r, & $r \cdot 1$ & 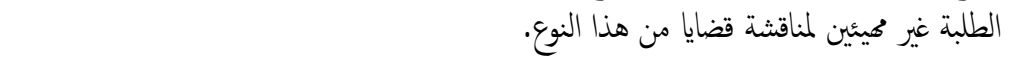 \\
\hline $1, \cdot \varepsilon$ & $\varepsilon, r_{0}$ & 191 & الوقت لا يكني لطرح مثل هذه القضايا للحاجها لجلسات نقاش وجمع معلومات من مصادر مختلفة. \\
\hline 1,17 & $\varepsilon, \wedge$ & $r \cdot 1$ & المصادر التي يكن للمعلم والطالب الرجوع إليها قليلة. \\
\hline 1,14 & $\varepsilon, 1 \Gamma$ & $r \cdot 1$ & التخوف من التأثير السلبي لطرح مثل هذه القضايا على فكر المتعلم. \\
\hline 1,1 . & $\varepsilon, 1$. & $r \cdot 1$ & ضعف عماراتي في مجال تدريس القضايا الجدلية. \\
\hline $1, \cdot v$ & $\varepsilon, 1$. & $r \cdot 1$ & ضعف خلفيتي المعرفية بالقضايا الجدلية. \\
\hline$\cdot .91$ & $r, 10$ & $r \cdot 1$ & 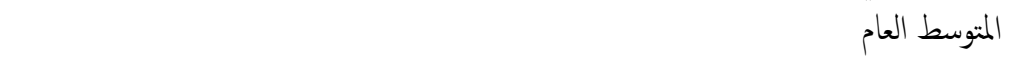 \\
\hline
\end{tabular}


مقارنة بخريجي تخصص جغرافيا - تاريخ الذين تركز مقرراتهم

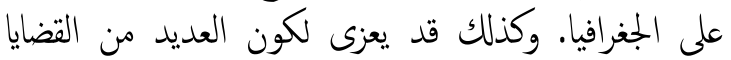

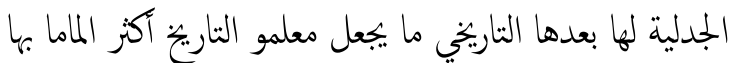

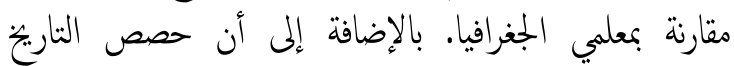

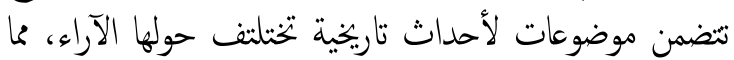

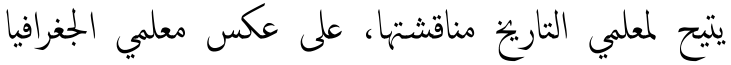

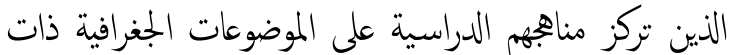
الطبيعة العلمية الصرفة.

مؤسسات إعداد داخل السلطنة متفقة إلى حد كير في

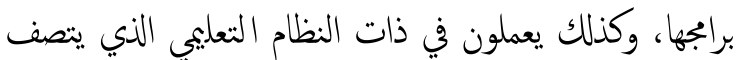

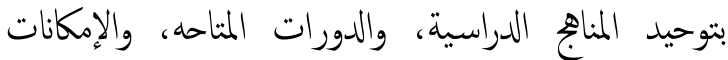

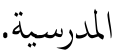

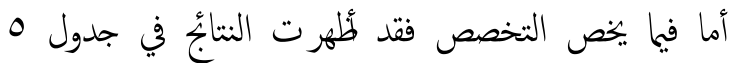

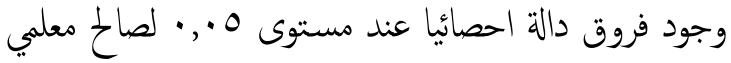

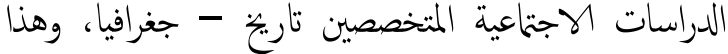

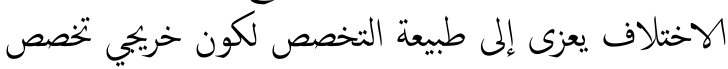

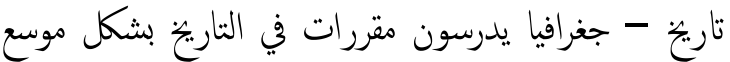

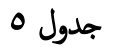

نتابُج اختبار (ت) لاتجاهات معلمي الدراسات الاجتاعية تبعا لمتغير التخصص المص المينة

\begin{tabular}{|c|c|c|c|c|c|c|c|}
\hline مستوى الدلالة & درجة الحرية & قيهة ت & المعياري & $\begin{array}{l}\text { المتوسطابي } \\
\text { المسبي }\end{array}$ & 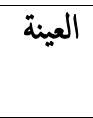 & التخصص & البجالات \\
\hline \multirow[t]{2}{*}{$\cdot, 199$} & $17 V$ & T70 & $\cdot, 1,000$ & $r, V I$ & 1.0 & جغرافيا- تاريخ & أهمية تدريس القضايا الجدلية \\
\hline & $11 T, V 7 \varepsilon$ & & $\cdot, 9 r \cdot 0 \mathrm{~V}$ & $r, v \varepsilon$ & $7 \varepsilon$ & تاريخّ- جغرافيا & \\
\hline \multirow[t]{2}{*}{$* ., \cdot \cdot$} & $17 V$ & $r, 7\rceil$. & $\cdot$, vлrq & $r, \Sigma 77 V$ & 1.0 & جغرافيا- تاريخ & بتقديم الضضايا الجدلية في غرفة \\
\hline & $\mid T \cdot, \sum T V$ & & $\cdot$ - AדTr & $r, V 990$ & $7 \varepsilon$ & تاريخّ" جغرافيا & الصف \\
\hline \multirow[t]{2}{*}{$\cdot, 1 \varepsilon$} & $17 \mathrm{~V}$ & $r, \varepsilon V T$ & $\cdot, \Lambda T V \cdot r$ & r,Y 19 & 1.0 & جغرافيا- تاريخ & التحديات التي تواجه تدريس الضضايا الجدلية \\
\hline & $|r \pi, \wedge \mu|$ & & $\cdot, \lambda r V \varepsilon 0$ & $\varepsilon, 0 \leqslant V$ & $7 \varepsilon$ & تاريخ- جغرافيا & \\
\hline \multirow[t]{2}{*}{$\cdot, \cdot r \cdot *$} & $17 V$ & r, 194 & $\cdot, 094 \cdot 9$ & ג, & 1.0 & جغرافيا- تاريخ & المتوسط العام \\
\hline & $1 \cdot 0, \wedge \wedge \varepsilon$ & & $\cdot, v 911 r$ & ऍ,人ТVT & $7 \varepsilon$ & تاريخّ- جغرافيا & \\
\hline
\end{tabular}

جدول 7

نتاجُ تحليل التباين الاحادي لمتغير المبرة

\begin{tabular}{|c|c|c|c|c|c|c|}
\hline مستوى الدلالة & قيمة ف & متمبط & درجة الحرية & بمجوع المربعات & & \\
\hline \multirow[t]{3}{*}{${ }^{*} \cdot, \cdot r$} & $r, 001$ & T,IVE & $r$ & $\varepsilon, \Gamma \varepsilon V$ & بين الجمموعات & \\
\hline & & $\cdot, 711$ & 191 & $M r \cdot, 9 \vee 0$ & ضمن المجموعات & أهية تدريس القضايا الجدلية \\
\hline & & & $r \cdot$. & Iro,ret & المجموع & \\
\hline \multirow[t]{3}{*}{$\cdot, 11 \mathrm{~V}$} & $r, 177$ & $1, \varepsilon \cdot r$ & r & $r, \lambda \cdot \varepsilon$ & بين الجمموعات & 的 \\
\hline & & $\cdot, T \leqslant V$ & 191 & $\mid r \Lambda, Y \cdot r$ & ضمن المجموعات & $\begin{array}{ll}10 \\
11\end{array}$ \\
\hline & & & $r \cdot$. & $|r|, \ldots r$ & المجموع & \\
\hline \multirow[t]{3}{*}{$\cdot, 091$} & $\cdot, 0 Y V$ & 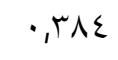 & r & $\cdot, \vee \vee \uparrow$ & بين المجموعات & \\
\hline & & $\cdot, \mathrm{V} \times 9$ & 191 & $1 \leqslant \varepsilon, r \leqslant 7$ & ضمن المجموعات & التحديات التي تواجه تدريس القضايا الجدلية \\
\hline & & & $r \cdot$. & $1 \leq 0, \cdot 1 \leq$ & المجموع & \\
\hline \multirow[t]{3}{*}{$\cdot, r \cdot \varepsilon$} & 1,191 & $\cdot, 019$ & r & $1,1 \vee \wedge$ & 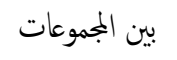 & \\
\hline & & $\cdot, \sum 94$ & 191 & $9 \vee, T \leq 1$ & ضمن المجموعات & الكلي \\
\hline & & & $r \cdot$. & 91,019 & المجموع & \\
\hline
\end{tabular}




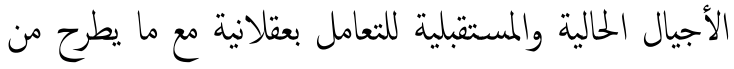
قضايا جدلية في الفضاء الإعلاي المفتوح.

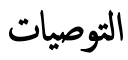

من خلال النتائُج توصي الدراسة بما يأتي:

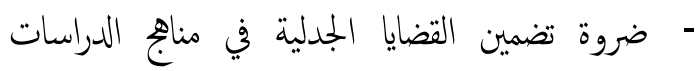
الاجتاعية بسلطنة عان.

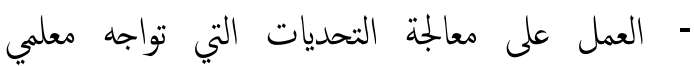
الدراسات الاجتماعية بطنة عان عند تدريس القضايا الجدلية. - المرات

تشجيع معلمي الدراسات الاجتماعية على تقديم القضايا الجدلية في المواقت الصفية.

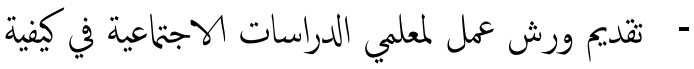

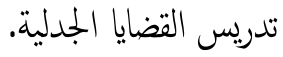

\section{المـاجع}

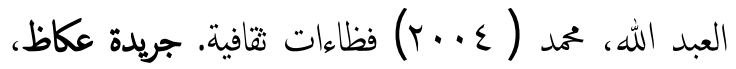

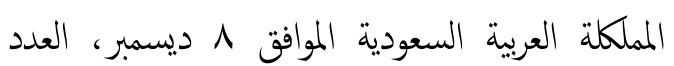

I TV.

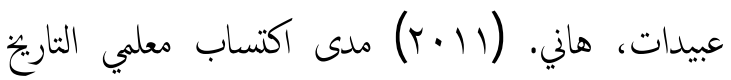

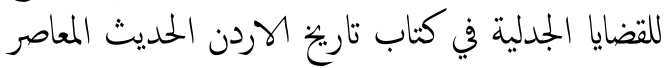

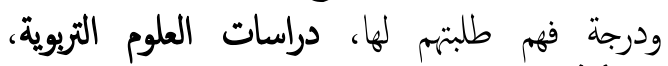

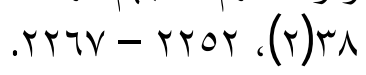

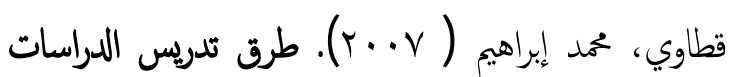

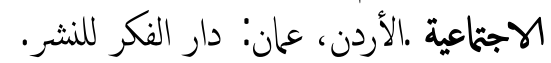

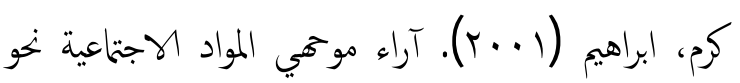

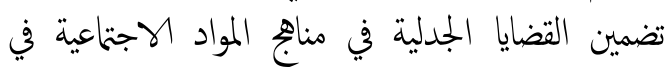

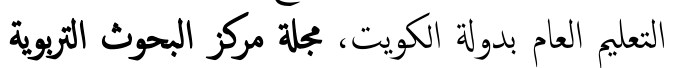

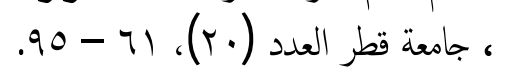

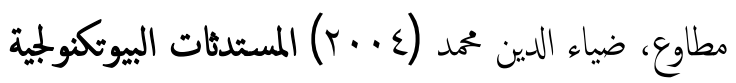

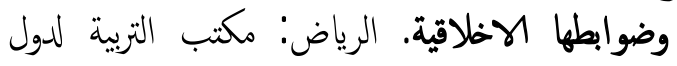

$$
\text { الخليج العربي. }
$$

Al-Rabaani, A hmed, (2014).The views of 0 mani Social Studies teachers about the inclusion of controversial issues in the Social Studies curriculum, INTCESS14 International Conference on Education and Social Science, Istanbul, Turkey, 3-5/ 2/ 2014.
وفيم يخص متغير المحافظة فقد ظُلهرت النتائج عدم وجود

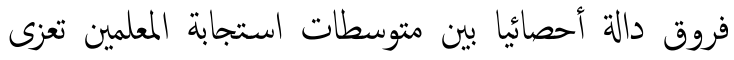

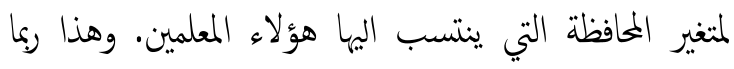

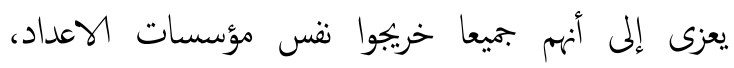

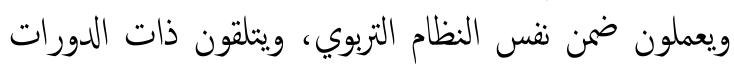

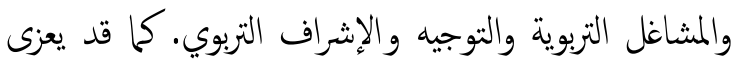

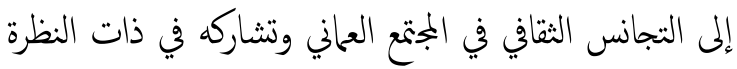

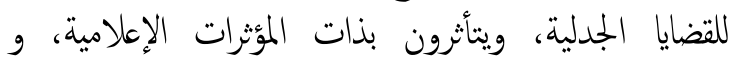

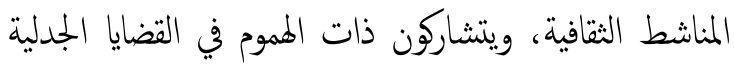
ذات الصلة بالوطن، وبالأمة العربية والإسلامية.

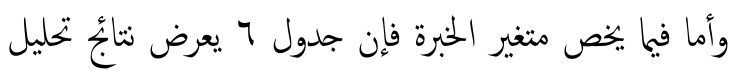
التباين إذ ظهرت فروقات حسب سنوات الخبرة.

تظهر النتائج في جدول 7 عدم وجود فروق دالة إحصائيا بين

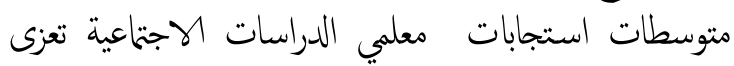

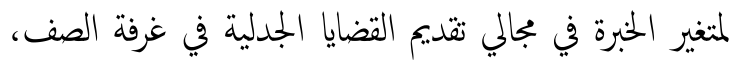

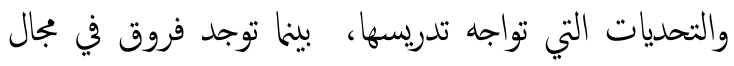

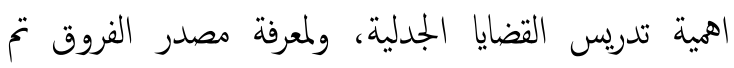

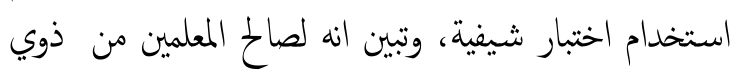

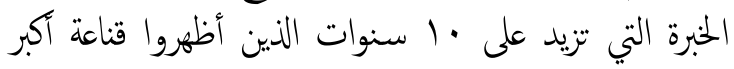
بأهمية تدريس القضايا الجدلية.

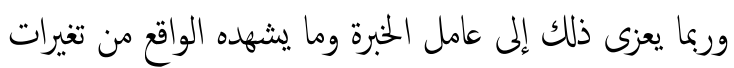

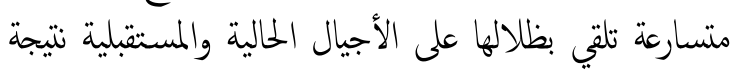

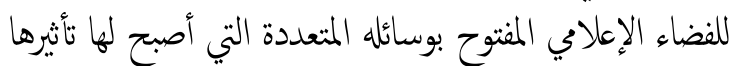

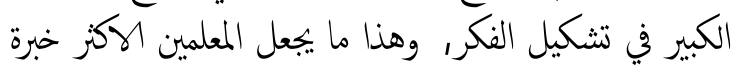

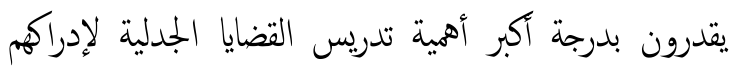

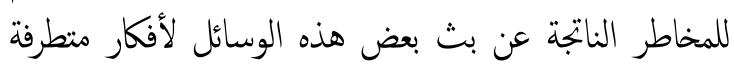

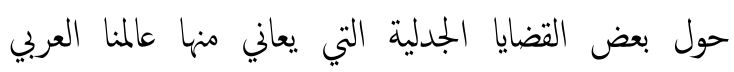
والإسلاي والذي قد يكون له انغكاسته السلبية على الطلبة.

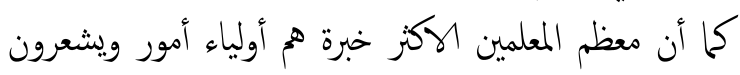

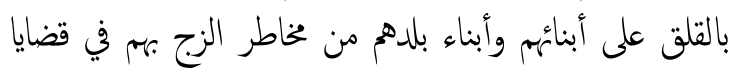

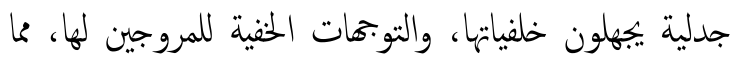

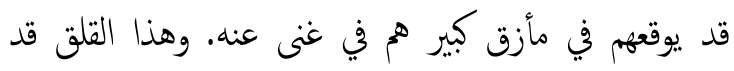

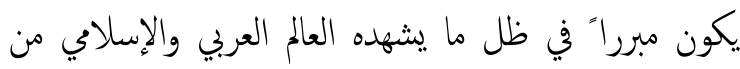

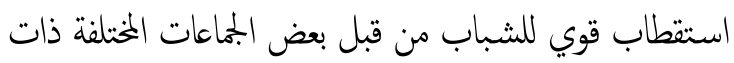

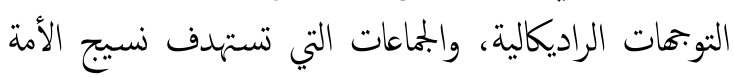

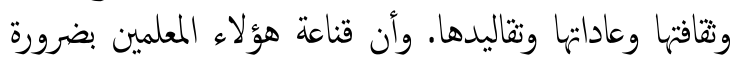
تدريس القضايا الجدلية هي نابعة من إدراكهم لأهمية تمكين 
Asimeng-Boahene, L. (2007). Creating strategies to deal with problems of teaching controversial issues in social studies education in African schools. Intercultural Education, 18, 231-242.

Ballagh, P. \& Sheppard, K. (2004). Creating an inclusive classroom environment with a globalperspective In M. Evans \& C. Reynolds (Eds.), Educating for global citizenship in achanging world. OISE: OISECIDA Project.

Baron, J. (2000). Thinking and deciding. Cambridge Press.

Brookfield, S. D. \& Preskill, S. (2005). Discussion as a way of teaching (3rd ed.). San Francisco: Jossey-Bass.

Brum, D. M., Bouldin, S. and White, C. (2000). Transforming the social studies curriculum in Issues in Social Studies: Voices from the classroom. Charles C. Thomas Pub: Springfield.

Cherryholmes, C. H. (2006). Visions, consequences and construction of social studies education.In A. Segal, E.E. Heilman, E., \& C.H. Cherryholmes (Eds.), Social studies the nextgeneration: Researching the postmodern (pp. 255-257). New York: Peter Lang.

Cotton, D. R. E. (2006a). Implementing curriculum guidance on environmental education: Theimportance of teacher's beliefs. Journal of Curriculum Studies, 38(1), 67-83.

Crumley, C. L. (2002). Exploring venues of social memory. In M. G. Cattell \& J. J. Climo (Eds.), Social memory and history: Anthropological perspectives (39-52). Walnut Creek, CA: Altamira Press.

Dube, O . . (2009). Addressing current controversial issues through the social studies Curriclum: Making social studies come alive. European Journal of Educational Studies, 1(1) 25- 34.

Ersoy, A. (2010) Social studies teacher candidates' views on the controversial issues incorporated into their courses in Turkey, Teaching and Teacher Education, 26, 323-334.
Freire, P. (1998). Pedagogy of freedom. Ethics, democracy and civic courage (P. Clarke, Trans.).N ew York: Littlefield.

Gallard, A., Abiteboul, S., Marian, A., \& Senellart, P. (2010). Corroborating information from disagreeing views. In Proceedings of the 3rd ACM International Conference on W eb Search and Data M ining (W SD M ) (131-140). ACM .

Hare, W., \& Portelli, J. P. (Eds.). (2001). Philosophy of education: Introductory readings (3rdEd). Calgary: Detselig.

Hess, D. (2001). Teachings do public controversy in a democracy? In J. J. Patrick $\&$ S. Robert (Eds.), In principles and practices of democracy in the education of social-studies teacher: Civic learning in teacher education (87-110). (ERIC DocumentationReproduction Service No. ED460064).

Kincheloe, J. L. (2005). Critical pedagogy. New York: Peter Lang

Lockwood, A. L. (1996). Controversial issues: The teacher's crucial role. Social Education, 60(1), 28-31.

Lockwood, A., \& Harris, D. (1985). Reasoning with democratic values: Ethical problems inU nited States history. N ew York: Teachers College Press.

Marsh, C. ed (2005).Teaching Studies of Society and Environment, Pearson Publication, Australia.

Oulton, C., Day, V., Dillon, J., \& Grace, M. (2004). Controversial issues - teachers' attitudes and practices in the context of citizenship education. Oxford Review of Education, 30(4), 490-507.

Oxfam House. (2006). Global Citizenship Guides: Teaching controversial issues. Retrieved from:www.oxfam.org.uk/ publications.

Parker W. C. (2001). Social Studies in Elementary Education (11th Ed). New Jersey: Merrill Prentice Hall.

Patrick, J. J., \& Vantz, T. S. (2001). Components of education for democratic citizenship in the preparation of social studies teachers? In J. J. Patrick \& S. Robert (Eds.), In principles and practices of democracy in the education of social studies teacher: Civic learning in teacher education (39-64). (ERIC 
Documentation Reproduction Service No. ED460064).

Stradling, B. (1985). Controversial issues in the curriculum. Bulletin of EnvironmentalE ducation, 170, pp.9-13.

Stronck, D. R. (2002). Teaching controversial issues of bioethics. In Proceeding of the annual international conference of the association for the education of teachers in science, Charlotte, NC, (ERIC Documentation Reproduction Service No. ED465619).

Suh, B., Chi, E. H., Kittur, A., \& Pendleton, B. A. (2008). Lifting the veil: Improving accountability and social transparency in Wikipedia with WikiDashboard. In Proceeding of the 26th annual SIGCHI Conference on Human factors in Computing Systems (1037-1040). ACM.

Summers, M., Corney, G., \& Childs, A. (2003). Teaching sustainable development in primaryschools: An empirical study of issues for teachers. Environmental Education Research, 9(3), 327-346.

Taber, C. S. \& Lodge, M. (2006). Motivated skepticism in the evaluation of political beliefs. A merican Journal of Political Science, 50(3), 755-769.

White, C., \& Walker, T. (2000). Issues-centered social studies. In C. White (Ed.), Issues in social studies: Voices from the classroom (99108). Springfield, IL: Charles C. Thomas Publisher.

Winkle, T. V. (2000). Citizenship Education in Issues in Social Studies: Voices from the classroom. Thomas Pub: Springfield.

Wu, M. \& Marian, A. (2007). Corroborating answers from multiple Web sources. In Proceedings of the 10th International W orkshop on Web and D atabases (W ebD B). (1-6).

Zoric, T., Ast, D., Lang, H., Vamvalis, M., Weber, M., \& Wong, M. (2004). Examining social justice and our human rights: Developing skills of critical inequity. In M. Evans \& C.Reynolds (Eds.), Educating for global citizenship in a changing world. OISE: OISECIDA Project. 